\section{JIBM}

Journal of International Business and Management (JIBM) Journal Homepage: https://rpajournals.com/jibm

\title{
Enhancing the Effectiveness of Change Management in Private Universities: Case Study in Vietnam
}

\author{
Thanh Uyen Pham Thi \\ The Vietnam National Institute of Educational Sciences, Vietnam
}

\begin{abstract}
Change management is known to be a significant model based on theories and practices from educational experts, educators, professors, school administrators, and even scientists. Like other higher education institutions in Vietnam, Private Universities in Ho Chi Minh city are a change management type organization. The management challenge facing contemporary universities refers to the multiple roles assumed by universities and the extraordinary increase in the number of subject fields, heightening, in turn, the complexity of the university environment. However, the previous research about change management of the Vietnamese private university system still has many shortcomings and limitations in terms of both size and quality. There is a lack of studies that have used Kotter's Model of Change (1996) to examine the evolutionary changes and challenges facing Private Universities. So, the main objective of this paper is to establish and propose a suitable model based on the apply Kotter's eight-step model of change to enhance effective change management in private universities in Ho Chi Minh City, and then discussion and recommendation will be presented in the study. To overcome the change challenges, some recommendation was proposed for the successful implementation of the changes for the university. Quantitative method has been utlised to complete this paper.
\end{abstract}

Keywords: change management, educational administration, Kotter's change model, private university, Vietnam

*Corresponding author: Thanh Uyen Pham Thi; Email: uyenpham123vn@gmail.com DOI: https://doi.org/10.37227/JIBM-2021-12-2096

\section{Introduction}

Now more than ever, higher education finds itself at a crossroads where traditional views of education's intrinsic value collide with market needs and the desires of key constituents, stakeholders, or customers (Baker \& Baldwin, 2015). Change can be difficult in higher education for several reasons, not the least of which is that any change from the status quo involves inherent risk (Beattie et al., 2013). There is a risk that people will not understand the new way of doing things and will either feel or become less valuable to the organization. There is a risk that some will lose their "expert" status or prestige if they were critical in building the old way of doing things, and there is the risk that the proposed change will not produce the intended results. Change means going from the known to the unknown, and that involves risk and discomfort (Kotter, 1996). Many would rather be certain of the outcome in their current situation than risk loss or failure by trying something different, even if there is 
a high probability the change's outcome will produce more favorable results. Nevertheless, if institutions of higher education are to remain relevant in educating the public, they must adapt to their environment and the ever-evolving needs of the market, society, their students, and students' parents. Given the highly competitive, educational institutions, operate, it is becoming increasingly important for organizations to gain competitive advantage by being able to manage and survive change (Amagoh, 2008). Change efforts evoke feelings and responses of resistance, anxiety, fear, hostility, uncertainty, opposition, and doubt. Many change efforts often failed not because the path to change or the reason for change was bad but because the strategies and approaches used to affect the change were flawed. Given the inevitability of change, organizations that will succeed, and have succeeded are those that have implemented change strategies that work.

Universities, as well as schools, must be continuously taking part in the process of change, or they will not be successful with their students given the ever-changing needs of society (Speck, 1999). In 1986, Vietnam started the economic renovation, which is often referred to as economic reform 1 . The economic reform replaced a central planning economy with a regulated market one, contributing to the country's high economic growth rates since the late 1980s (WB, 2012). National education reforms since the early 1990s have seen many major changes. The country is also facing challenges and opportunities. Regarding challenges, Mac Cargo (2003) states that the reforms have resulted in a rapid increase in the numbers of students, numbers, and types of educational institutions and courses of studies at all levels of education. He adds that; however, the national education system seems to be facing deterioration in quality. Concerning opportunities in the higher education environment, when being asked by Viet Nam News on May 31, 2006, Deputy Minister of Vietnamese Education and Training, Banh Tien Long stated that the overall objective of tertiary reform in the next 15 years (the country's global integration plan for education from 2006 to 2020) would be to achieve basic changes in the quality and scope of the system so that it could respond to the socio-economic development and the people's demands for further studies. By the same token, Hung (2007), conveys five challenges, which include: the comparability of quality and standards; the multi-nationalization of higher education; the problem of brain drains; the problem of intellectual property; and maintaining a university as a learning organization. Regarding the roles of leaders in the transformation of Vietnamese higher education, Hung (2007) suggests that Vietnamese universities need a radical transformation to improve the quality and effectiveness of education to meet the diversified demands for human resources. However, the decentralization must be affected in a step-by-step manner. The university needs a planned sequential path: The management of change needs to be considered and upgraded in the whole process of change. In this article, the author used Kotter's Model of Change (1996) for the governance of Private Universities in Ho Chi Minh City.

\section{Literature Review}

\section{Overview of the Private University in Vietnam}

Developing private universities has become an inevitable trend, and private universities are increasingly asserting their role in the world education system. With the policy of extensive and comprehensive integration with the world, Vietnam is no exception to that trend. Over 30 years of establishment and development, Vietnamese private universities have made many important contributions to the development of the country in general and the education and training industry. Up to now, Vietnam has 60 private universities, accounting for $25.5 \%$ of the total number of universities in the country, distributed in 29/63 provinces/cities. In 
which, the big cities with many private universities are Hanoi with 13 schools, Ho Chi Minh City. Ho Chi Minh City 12 schools; The training scale of private universities is more than 253 thousand students, accounting for $13.16 \%$ of university students nationwide with a teaching staff of about 20,500 people. Up to now, many private universities have built spacious and modern facilities, some of which have been built according to international standards. Thereby, private universities have contributed to the improvement of the higher education system. However, the Vietnamese private university system still has many shortcomings and limitations in terms of both size and quality. Therefore, this study applies Kotter's model of change governance in the private education system in Ho Chi Minh City concerning what approaches and strategies are considered effective in the educational administration of the private university.

\section{Kotter's 8 Step Model of Change}

John Kotter, professor at Harvard's School of Business, created two models of change management. Both were designed for businesses to competitively adapt to their environment. Kotter's original model (1996) for change was hierarchal and required a stepped approach until a tipping point for change occurred. Sang et al. (2020) applied Kotter's 1996 model to facilitate change in higher education. Sang's application of Kotter's stepped model in a higher education environment stalled due to multiple barriers. The barriers included dynamic changes in faculty, educational practices, faculty autonomy and their lack of involvement in the process. The hierarchical style of Kotter's 1996 model, combined with its stepped and linear approach.

In generic management and organization science, the eight-step model for successful implementation of organizational change by Jonh Kotter (1996) is well-known and widely accepted. The eight steps include: (1) Establishing a sense of urgency. A sense of urgency is crucial in the initial stages of the process. It must primarily overcome any sense of complacency within the organization. (2) Creating the guiding coalition. A core group with enough power to lead the change through the transition state is required to drive the process. (3) Developing a vision and strategy. A vision needs to be created to direct the course of change. In conjunction with the vision, there should be a strategy designed to achieve the vision. (4) Communicating the change vision. The new vision and strategies for implementation of the change process need to be continually communicated using all practical means. (5) Empowering broad-based action. How to create an environment in which the actions required for change can take place. Critical empowering actions need to be taken to allow change to occur. (6). Generating short-term wins. Positive feedback in the early stages of the project is a critical success factor and plays an important part in sustaining the vision e.g., through the achievement of interim targets, short-term wins. (7) Consolidating gains and producing more change. Systems, structures, and policies may be further adapted to be in line with the vision. (8) Institutionalizing new approaches. Maintaining the results of change in organizational, group, and individual culture is crucial, creating better performance through effective management and leadership development and succession. 


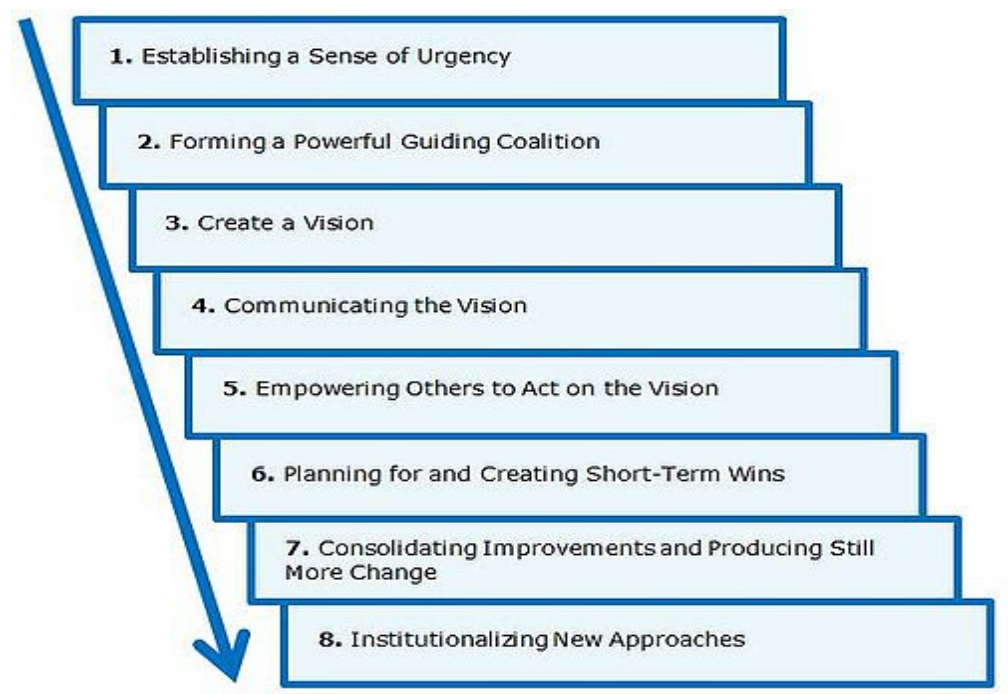

Fig 1. Kotter's 8 step model of change

\section{Uses of Kotter's Change Model in Higher Education Institutions}

Educational institutions, both private and public, have been forced to adapt to competition as government funding is no longer guaranteed. In addition, these institutions are being forced to find ways of collaboration. Hecht (2013) noted that given the combination of shrinking demand, diminishing support, and intense competition, organizations individually could not confront the complex and interconnected problems of modern society. To survive, organizations must adapt to a new world order of global competition and collaboration. Both modes of functioning require that organizations change their business processes and systems, but more importantly, change the cultures of their organizations as well as the attitudes, behaviors, and consciousness of their employees. Changing systems may simply require new policies and technologies. But changing employee behavior can be complex, timeconsuming, and hard to accomplish.

Kotter's change model has been used to successfully guide or account for the change in higher education settings but is generally related to administrative and technological changes. For instance, Wentworth, Behson, and Kelley (2018) reported on their use of Kotter's change model to replace a teaching evaluation system. They attributed their success to their adherence to Kotter's steps, but also explained how these steps fit within a higher education context. They noted the importance of including members elected by the faculty on the guiding team to fit within the shared governance model and gain faculty buy-in. When communicating the vision to faculty, they helped faculty understand how the new system could provide benefits in tenure and promotion processes, including by providing faculty with more useful and timely feedback. Likewise, they took care to be transparent in communicating how and why they chose a specific system.

\section{Methodology}

The research was designed around one case study site, the Private Universities in Ho Chi Minh city, and the method used in this study is a quantitative research method based on surveys. Secondary data of study was collected from Universities secondary sources. A set of questions was developed based on the key variables identified in the conceptual framework of the change management model. Information was also collected from a separate set of structured interviews with university management (deans/department heads) and 
faculties, staff, and students to support case analysis. Statistical used is the descriptive analysis. The collected data was analysed in the descriptive analytical process that have been outlined in the next results and discussion section.

\section{Results and Discussion}

This section will be presenting the findings of management challenges of change at the Private Universities in Ho Chi Minh city. The discussion will be based on the theoretical model of change, especially based on the change model of John Kotter's Eight Phase Model (1996).

\section{Create a Sense of Urgency to the Need for Change}

According to the figure 3 the results of study showed that $40 \%$ of the respondents presented sometime for the creating a sense of urgency to the need for change. There are $35 \%$ argued that rarely to create a sense of urgency for university change and $12 \%$ said mostly.

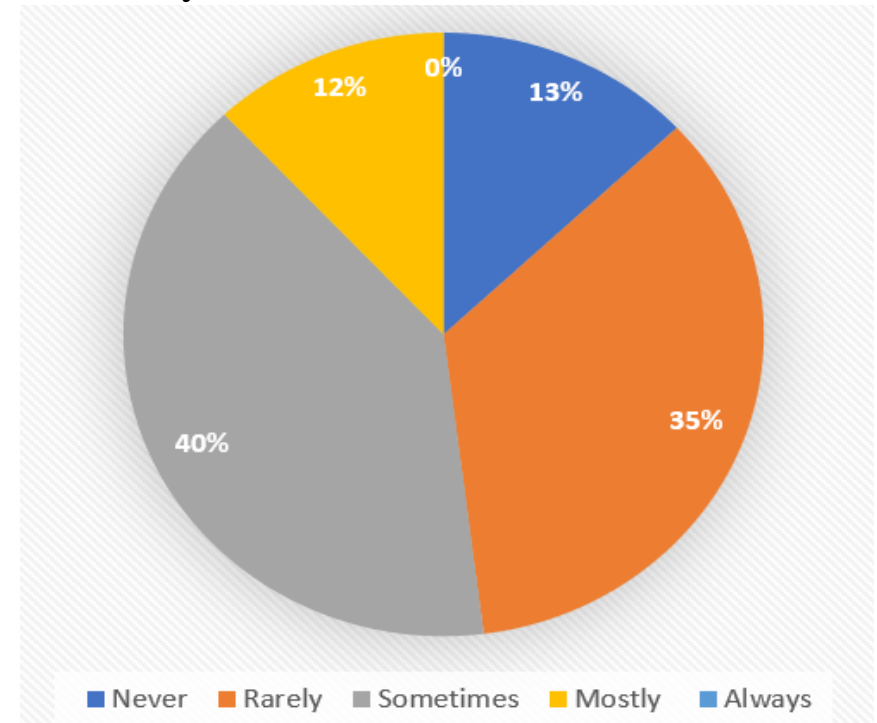

Figure 3: Create a sense of urgency to the need for change

\section{Provide Evidence to Persuade the Need for Change}

Based on the interview, there are $40 \%$ of the respondents argued that it is rarely providing evidence to persuade the need for a change of Private Universities, they said that sometimes the change initiated from the top management without clear evidence to support the need for change. For example, renovation of the building, conference room, library, campus environment, etc., they mentioned that other things such as toilets, cleaning, garbage controlling, classroom facilities, Internet capacity, that all proved the need for change, however, they are still not the priority. There are $29 \%$ of respondents provided that the Private University has never provided clear evidence of the need for change and $28 \%$ of the respondents believed that there are sometimes. 


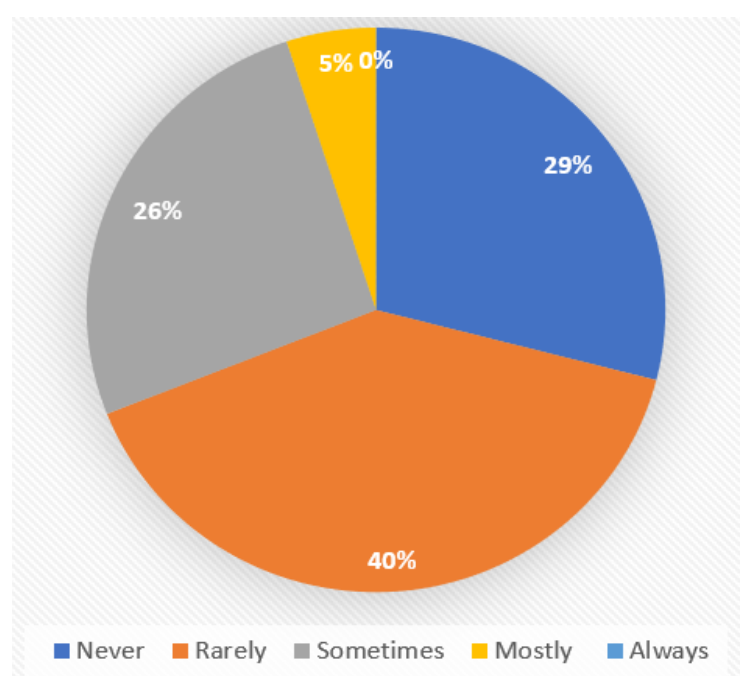

Figure 4: Provide evidence to persuade the need for change

\section{Creating a Clear Vision for Change}

Figure 5 indicated that there are $46 \%$ of the respondents argued that they are not clear about the vision of the university for change. They criticized that the vision of change did not provide a chance for discussion. They said that the vision statement is created by top management and without participation and consultation so that it is too broad for achievement. They said that it is very important for the vision of the change to develop a commitment of faculty and staff, to support the implementation of change if they are clear about what we are going to do and how to do it. However, $24 \%$ argued that it was sometimes the vision has been explained and did not clear. At least $17 \%$ of the respondents believed that the vision for change has been created clearly and only $13 \%$ of respondents provided never.

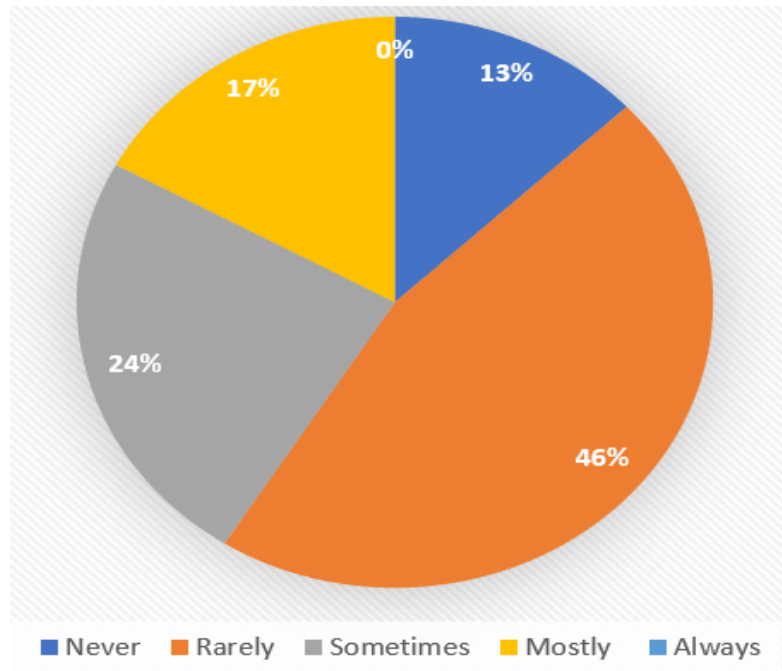

Figure 5: Create a clear vision for change

\section{Develop Effective Strategies to Deliver the Vision of Change}

Figure 6 showed that $48 \%$ of the respondents said that there is rarely to the development of effective strategic actions to deliver the vision of change. Most of the respondents said that there were no clear action plans for delivering the vision of change, they said the university should have workshops and training at least three to four times to make 
understanding of how to implement the strategies and this is the way to offer the opportunity for faculty and staff to develop a commitment of change. There are $20 \%$ of the respondents provided sometimes and $19 \%$ presented mostly.

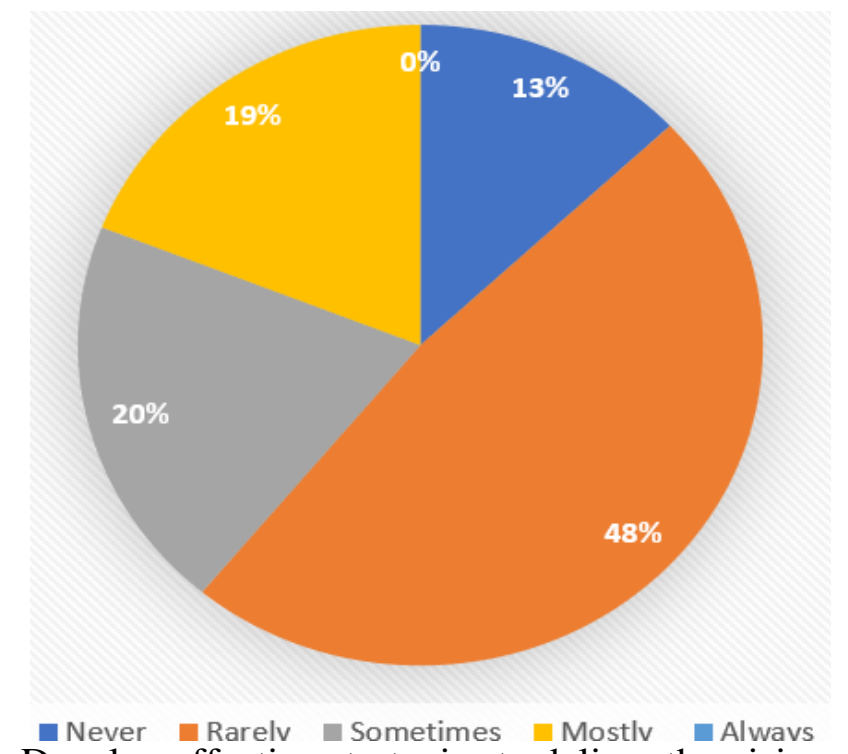

Figure 6. Develop effective strategies to deliver the vision of change

\section{Clear Roles and Structure to Deliver the Change Vision}

There are $40 \%$ of the respondents indicated sometimes to encourage people to take account to deliver the change vision. They said that their lack of positive motivation, sometimes, they work hard but it seems to be not recognized by the management. There are $35 \%$ of the respondents argued rarely of encouraging people to take into account for delivering the change vision, $19 \%$ said never and only $6 \%$ showed that mostly.

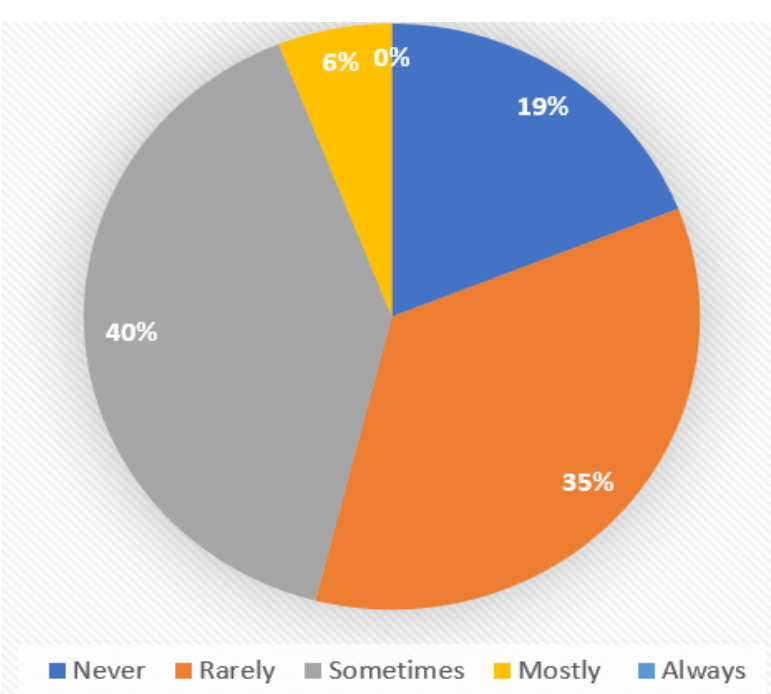

Figure 7. Encourage people take actions to deliver the change vision

\section{Attitude towards the University Changes}

The question on how your attitude toward the change of the Private Universities, in figure 8 showed that $66 \%$ of respondents hesitated to show positive or negative attitudes, they pointed that on neutral, means that they think there are not positive or negative. 
There are $15 \%$ of the respondents, however, showed that their attitudes are negative, and only $10 \%$ was positive. At least $4 \%$ of the respondents are very pessimistic about the attitudes toward the change of the University, they feel that the change did not gain more benefits to them and affected their relatives.

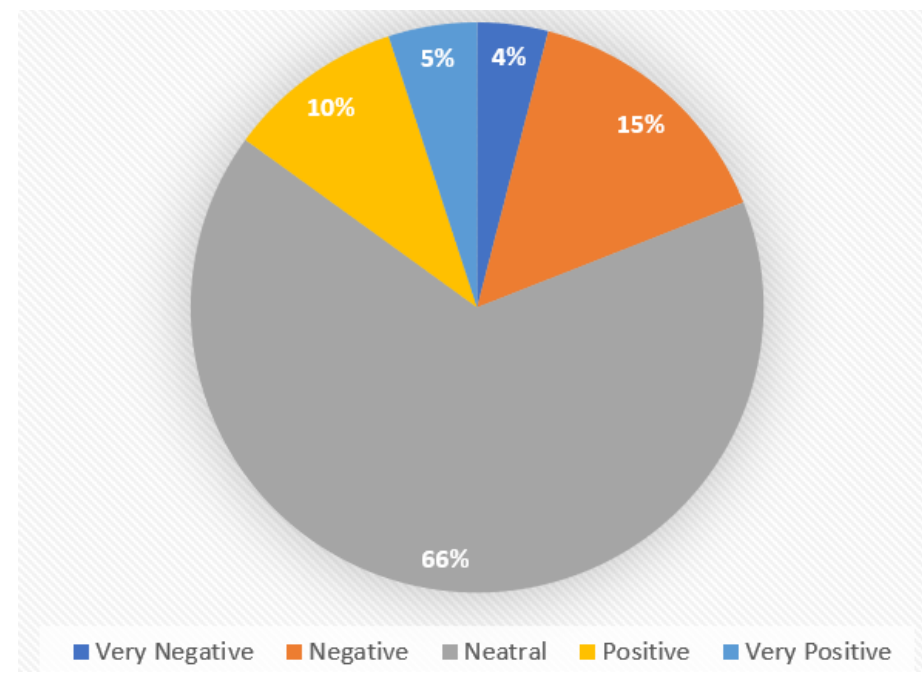

Figure 8: Attitude towards university change

\section{Satisfaction after Change}

Figure 9 indicated that $45 \%$ of the respondents are neutral on the satisfaction of work after change. According to the interview, most of them feel that their working places are small, facilities and technology are not sophisticated enough, there is no personal room for dean and faculty to work or consult with students, not enough stationery for work operations, no petty cash for solving a routine work problem, no staff support for each faculty, etc. There are $32 \%$ of the respondents, however, satisfied with workplace after the change, they feel proud with the new environment of the campus and $23 \%$ of the respondents are not satisfied with the change.

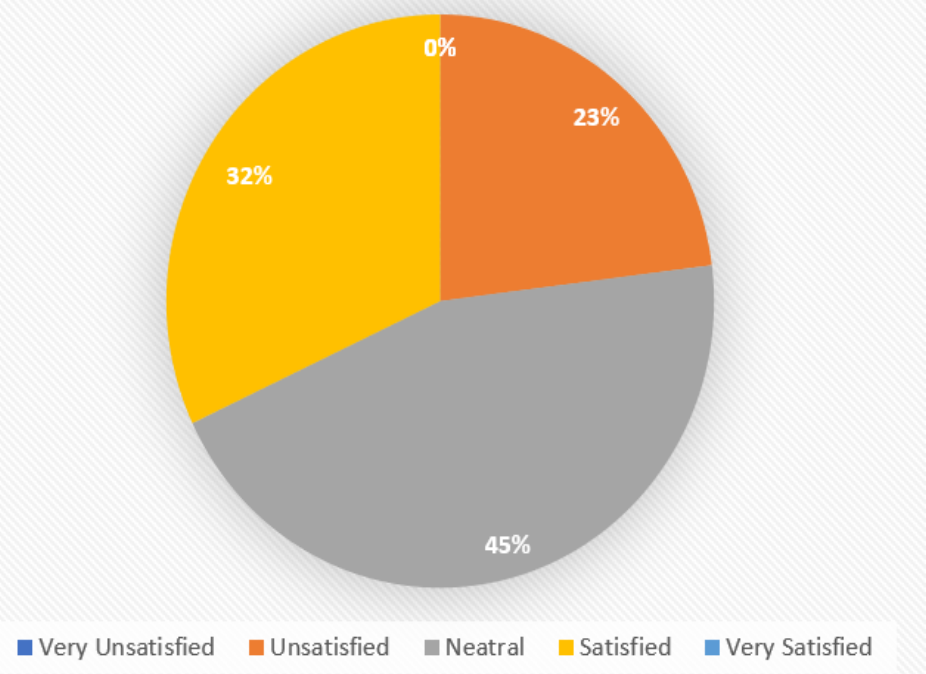

Figure 9: Satisfy with work after change 


\section{Implications and Conclusions}

This study has developed concepts, validity, reliability and assessed the influence of factors on change management in a university environment through results from interviews. It shows that most of the interviewees have a positive attitude towards change management and applying a new model to private universities. Regarding Private Universities in Ho Chi Minh City, Vietnam needs a new model for developing change management processes to fulfill its educational role in the Vietnamese and regional learning environment. Ho Chi Minh City as well as promotes integration into the global educational environment. Meanwhile, any educational institution in a country can certainly choose its suitable model to adopt, manage and develop a change management process for the educational goal of the country that family.

Change in higher education is hard, or at least it can be. Due to the decentralized organizational structure, shared governance, and several other factors that make higher education a unique place to live and work, it is commonplace to think it is nearly impossible for leaders to effectively implement significant change that is incongruent with the institution's organizational culture. This study provides evidence to the contrary. Leaders can successfully implement change-even change that is incongruent with organizational culture - if they first develop an in-depth understanding of the culture, spend some time researching their environment, and show strong evidence of a need for the change (Buller, 2015; Kotter, 1996). However, even a proven necessity will not motivate everyone to embrace change that is incongruent with long-standing tradition and organizational culture. Private Universities have many change experiences from period to period and more people are satisfied with the university after changes. The change of universities was responding to the change in environment such as national and regional competitions, government policy, market demands, etc. The Universities, however, achieved its mission by serving the nation by providing several thousands of capable and socially responsible managers and entrepreneurs for Viet Nam society. The University initiated many successes of changes such as improving physical infrastructure, upgrading technology system, developing curriculum, building the capacity of human resources, improving work conditions, redefining internal regulations and policy. The University achieved many things of change; however, current management of the changes are criticized by faculty staff and students such as do not clear vision and strategy for the change, insufficient communication, lack of commitment for the faculty and staff, lack of empowerment, and delegation for implementation, do not clear roles and responsibilities and lack of control mechanism for the implementation of change.

\section{Limitation \& Future Research}

There are some limitations in this study. Firstly, the study focuses on the management of change of the private universities of a city. However, the final research papers can develop the research scale. Secondly, the analysis method of this study is descriptive. However, the future researchers may use qualitative analysis for the deeper understanding. Furthermore, comparative studies between some universities are also recommended to the future researchers. 


\section{References}

Amagoh, F. (2008). Perspectives on organizational change: Systems and complexity theories. The Innovation Journal: The Public-Sector Innovation Journal, 13(3), 114

Baker, V. L., \& Baldwin, R. G. (2015). A case study of liberal arts colleges in the 21st century: Understanding organizational change and evolution in higher education. Innovative Higher Education, 40(3), 247-261.

Buller, J. L. (2015). Change leadership in higher education: A practical guide to academic transformation. Jossey-Bass.

Beattie, J., Thornton, B., Laden, R., \& Brackett, D. (2013). 21st-century challenges in higher education: Strategic changes and unintended consequences. International Journal of Educational Leadership Preparation, 8(1), 62-71.

Hecht, B. (2013). Collaboration is the new competition. Harvard Business Review Blog

Jolibert, A. \& Jourdan, P. (2006). Marketing research: méthodes de recherche et d'études en marketing. Dunod.

Kotter, J. P. (1996). Leading change. Harvard Business Review Press.

Kotter, J. P. (2014). XLR8: Accelerate. Harvard Business Review Press

McMillan, J. H. \& Schumacher, S. (2010). Research in Education: Evidence-Based Inquiry, My Education Lab Series. Pearson.

Speck, M. (1999). The principal ship: Building a Learning Community. Upper Saddle River: Prentice Hall.

Tong, A., Sainsbury, P. \& Craig, J. (2007). Consolidated criteria for reporting qualitative research (COREQ): a 32-item checklist for interviews and focus groups, International Journal for Quality in Health Care, 19(6), 349-357.

Quoc Hung, L. N. (2007). Transforming a university into a learning organization in the era of globalization: Challenges for the school system leaders. Essays in Education, 20(1).

Wentworth, D. K., Behson, S. J., \& Kelley, C. L. (2020). Implementing a new student evaluation of teaching system using the Kotter change model. Studies in Higher Education, 45(3), 511-523. 